\title{
Epilepsiechirurgie: psychiatrische ontwikkelingsproblemen bij kinderen
}

Aan de hand van een tweetal cases wordt het voorkomen van psychiatrische ontwikkelingsproblemen bij kinderen met epilepsie besproken, en de veranderingen hierin na epilepsiechirurgie. Ook wordt een relatie gelegd met de preoperatieve psychiatrische problematiek van het kind. De cases illustreren het belang om in het epilepsiechirurgietraject, naast de algehele ontwikkeling, ook de (psychiatrische) risicofactoren in kaart te brengen en te begeleiden.

Classificatie van epilepsie is van groot belang om de beste behandeling te kiezen. De kans dat een focale epilepsie, met een onderliggend structurele laesie of een genetische en metabole stoornis, vanzelf overgaat is zeer klein. Het vroegtijdig evalueren van de mogelijkheid van epilepsiechirurgie heeft in eerste instantie de voorkeur. Naast uitgebreide bronlokalisatie van de epilepsie, wordt de (psychiatrische) ontwikkeling van het kind geëvalueerd en wordt een inschatting gemaakt van de belastbaarheid van het kind en de draagkracht van het gezin. Zowel kind als ouders worden multidisciplinair begeleid. De eventuele aanwezigheid van een psychiatrische co-morbiditeit moet meegenomen worden in deze pre-, en ook postoperatieve, evaluatie van het epilepsiechirurgietraject.

\section{Casus I}

Een meisje, deel van een eeneiige tweeling krijgt haar eerste aanval op driejarige leeftijd. De aanval treedt op als het kind een oorontsteking heeft en een temperatuur van 38,3 graden. $\mathrm{Zij}$ reageert niet op aanspreken en heeft gedurende twintig minuten ritmische trekkingen in rechterarm en been, met weggedraaide ogen, speekselvloed en tongbeet. De diagnose koortsstuip wordt gesteld. In de familie komen geen epilepsie of koortsstuipen voor. Na deze aanval geeft zij meerdere keren per dag aan dat zij gedurende één minuut buikpijn heeft, waarbij zij stopt met handelen. Daarnaast is zij misselijk en heeft braakneigingen. De bevindingen van het neurologische onderzoek zijn niet afwijkend. Onder verdenking van een focale epilepsie wordt elders een EEG na slaap-deprivatie gedaan, dat een normaal achtergrondpatroon laat zien en trage activiteit links temporaal.

Omdat de diagnose epilepsie niet bevestigd kan worden, wordt zij naar Stichting Epilepsie Instellingen Nederland (SEIN) in Zwolle verwezen. Een 24-uurs video-EEG toont interictale epileptiforme activiteit links frontolateraal en temporaal links. Ook wordt een epileptische aanval geregistreerd uitgaande van links (laag) achter- en midden temporaal. Er wordt gestart met carbamazepine. De vele en soms langdurige aanvallen persisteren. Beeldvormend onderzoek (MRI) van de hersenen laat een aankleurende laesie zien, verdacht voor een ganglioglioom. Vanwege de hoge aanvalsfrequentie en verwachte gunstige prognose van epilepsiechirurgie, volgt in het Universitair Medisch Centrum Utrecht (UMCU) op driejarige leeftijd een laesionectomie links temporaal. Het corticale EEG-onderzoek peroperatief toont geen mesiotemporale betrokkenheid. De diagnose desmoplastisch infantiel ganglioglioom graad I, wordt door middel van pathologisch onderzoek bevestigd. De postoperatieve MRI van de hersenen laat een resectieholte en gliose links temporaal zien. Postoperatief is en blijft zij aanvalsvrij en de anti-epileptica worden in één jaar afgebouwd.

\section{Veranderend beeld}

Een jaar na de operatie krijgt patiënte aanvalsgewijze korte momenten van buikpijn, ruikt vieze geur, houdt de hand voor haar mond, heeft verstrakte kaken en slikt herhaaldelijk. Ook heeft zij grote bange ogen en een rood gelaat. Ze kan geen antwoord geven op vragen. Er worden soms focale motorische verschijnselen in de rechter lichaamshelft waargenomen. Het resultaat van een 24-uurs video-EEG toont een recidief van de epileptische aanvallen vanuit de regio links temporaal. De MRI van de hersenen laat nu een afwijkende signaalintensiteit en volumeverlies van de hippocampus zien, passend bij mesotemporale sclerose links temporaal. Er is geen aanwijzing voor een recidief gangioglioom. Een mesiotemporale resectie (hippocampus) volgt op ruim zesjarige leeftijd. De aanvallen die na enkele maanden terugkeren worden 
bestreden door uitgebreide aanpassing van de medicatie. De presentatie van de aanvallen in de spreekkamer verandert en is duidelijk anders dan voorheen. Ze valt stil, smakt, heeft een droevige blik en reageert niet op de omgeving. Zij meldt achteraf dat de geursensaties wisselend aanwezig zijn. Bij het andere type aanval, probeert zij te gaan staan, ervaart ze minder kracht in haar benen en laat een breedbasisch looppatroon zien, waarbij zij half door haar benen zakt. Tijdens het video-EEG onderzoek dat met spoed wordt gedaan heeft zij zeventien van dergelijke aanvallen zonder dat er ictale epileptiforme afwijkingen in het EEG voorkomen. De diagnose Psychogene Niet Epileptische Aanvallen (PNEA) wordt gesteld, naast de bekende diagnose epilepsie.

\section{Ontwikkeling kind}

Aanvankelijk is haar vroege ontwikkeling op niveau, zij spreekt de eerste woordjes bij tien maanden en gaat los lopen bij vijftien maanden. Preoperatief intelligentie onderzoek toont bij een kleutertest gemiddelde tot bovengemiddelde prestaties, met postoperatief vergelijkbare resultaten. Wel zijn er postoperatief gedragsproblemen, zich uitend in boosheid en opstandig gedrag, waarvoor speltherapie wordt gestart. In retrospect, worden wel bijzonderheden gezien qua emotiebeleving, omgaan met veranderingen en aangaan van nieuwe situaties. Pre- en postoperatief intelligentie onderzoek rondom de tweede operatie (op zesjarige leeftijd) bevestigen deze resultaten. Echter, na de tweede operatie krijgt ze steeds meer en gevarieerdere tics. Qua gedrag is ze verlegen en zijn er problemen in de sociale interactie. Wederom wordt speltherapie ingezet met voldoende effect.
Herhalingsonderzoek in verband met PNEA en tics (ze is dan inmiddels ruim negen jaar) laat weer gemiddelde resultaten zien, conform schoolresultaten en voldoende ontwikkeling ten opzichte van eerder onderzoek.

Anamnestisch zijn er meerdere gedragsbijzonderheden. Ze heeft moeite met overgangsmomenten en heeft veel behoefte aan duidelijkheid, regels en structuur. Ook vallen problemen op in de sociale context qua taal. Haar PNEA lijkt te ontstaan op overgangsmomenten of onduidelijkheid, evenals haar tics. Er ontstaat een verdenking op een (lichte vorm van een) Autisme Spectrum Stoornis. Diagnostiek en multidisciplinaire begeleiding van de PNEA door de psycholoog, psychomotore therapeut en speltherapeut van SEIN is inmiddels afgerond. Ze is verwezen naar de kinderpsychiater voor diagnostiek en begeleiding van haar Autisme Spectrum Stoornis en tics, wat hopelijk ook een gunstig effect op de PNEA zal hebben.

\section{Casus 2}

De tweede casus is een tiener, bekend met het attention deficit hyperactivity disorder (ADHD) syndroom en een stoornis in het autisme spectrum. De familieanamnese voor epilepsie is negatief. Op tweeëneenhalfjarige leeftijd is zij van de trap gevallen, op de stenen vloer. Toen zij drie jaar was had zij haar eerste aanval. De aanval begint met het ruiken van een geur. $\mathrm{Zij}$ ziet een gekleurde bol, beginnend boven, steeds dichterbij komend en verspreidend, tot zij deze met beide ogen ziet. Dit fenomeen is altijd hetzelfde, meerdere keren per dag, enkele seconde durend, zonder hoofdpijnklachten. Aanvankelijk wordt dit geduid als migraine, maar vanwege een toenemende dagelijkse aanvalsfrequentie, verwijst de kinderarts haar op vijftienjarige

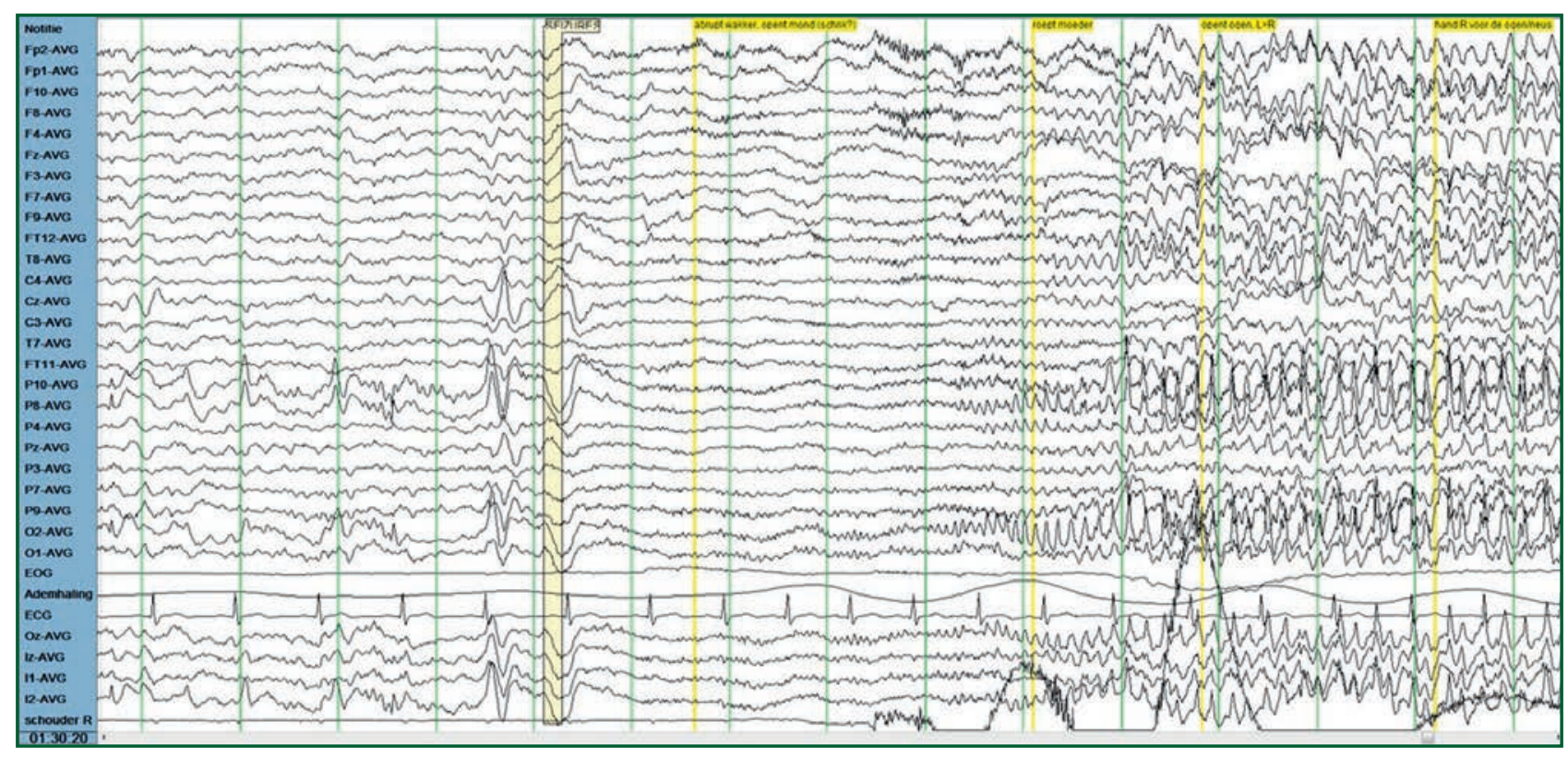

Figuur I Het EEG gemeten tijdens een video-EEG onderzoek weergegeven ten opzichte van de gemiddelde referentie (AVG), plus het ECG, de ademhaling (oz, lz, i1 en iz ten opzichte van AVG) en het EMG. Vanaf de marker 'Seizure' begint de epileptiforme activiteit rechts occipitaal/ parieto-occipitaal. 
leeftijd naar SEIN. De verdenking op een focale epilepsie wordt bij SEIN bevestigd door middel van een 24-uurs video-EEG, dat interictaal epileptiforme afwijkingen rechts achter temporaal-parieto-occipitaal laat zien en aanvallen (ictaal) beginnend rechts occipitaal/parieto-occipitaal (figuur I).

\section{Onderzoeken}

Het resultaat van neurologisch, oogheelkundig en gezichtsveldonderzoek is normaal. De 3T-MRI van de hersenen toont gliose rechts parieto-temporaal met ter plaatse weefselverlies, waarschijnlijk ten gevolge van het doorgemaakte hoofdtrauma. Er wordt gestart met carbamazepine. Maar vanwege persisteren van dagelijkse aanvallen wordt lamotrigine toegevoegd, helaas met onvoldoende effect. De mogelijkheid van epilepsiechirurgie wordt geëvalueerd. Positron Emissie Tomografie (PET) toont een hypometabolisme rechts parieto-occipitaal. Onderzoek met een elektrodengrid dat enkele dagen onder de schedel geplaatst wordt voor onderzoek naar de locatie van de epilepsiehaard bevestigt het rechts parieto-occipitale begin van de epileptische aanvallen. Een succesvolle resectie volgt op de leeftijd van achttien jaar. Patiënte blijft aanvalsvrij en na zes maanden wordt gestart met een langzame afbouw van de medicatie.

\section{Ontwikkeling kind}

De vroege ontwikkeling verloopt naar tevredenheid. Zij behaalt op het speciaal onderwijs, waar ze vanwege haar ADHD en Autisme Spectrum Stoornis terecht kwam, haar VMBO-TL diploma.

De preoperatief neuropsychologische evaluatie toont een cognitief profiel passend bij haar schoolniveau en eerder gestelde diagnose. Wel is er een verhoogde psychische lijdensdruk, waaronder angst en somberheid, waarvoor uitgebreide begeleiding wordt verzorgd door SEIN. Ondanks de succesvolle epilepsiechirurgie, gaat het aanvankelijk helemaal niet goed met patiënte. Zij heeft aanvalsgewijze visuele verschijnselen, maar met een andere presentatie dan voor de operatie. Ook een enkele keer heeft zij trillingen over het gehele lichaam, wat niet geduid wordt als epilepsie. Postoperatief toont perimetrisch oogheelkundig onderzoek, zoals te verwachten, een defect van het onderkwadrant links voor beide ogen. Een herhaling van het 24-uurs video-EEG toont geen epileptiforme afwijkingen. De postoperatieve neuropsychologische evaluatie toont resultaten conform preoperatief onderzoek. Na de operatie start zij met een mboopleiding niveau 3, maar zij doubleert het eerste jaar, ondanks extra begeleiding. De psychische lijdensdruk is hoger dan preoperatief. De angst, en de depressieve en vermoeidheidsklachten blijven lange tijd voortbestaan. Ondanks voldoende cognitieve vermogens lukt het haar nog niet om een opleiding goed af te ronden danwel een baan te vinden. Haar behandeling richt zich nu op acceptatie van beperkingen en omgaan met autisme.

\section{Achtergrond}

Voor kinderen met therapieresistente focale epilepsie is epilepsiechirurgie de meest effectieve en veilige behandeling. Na zorgvuldige selectie biedt epilepsiechirurgie de meeste kans op aanvalsvrijheid (Baud et al., 2018). In Europa wordt epilepsiechirurgie bij kinderen, sinds de start veertig jaar geleden, op een jongere leeftijd en na kortere duur van de epilepsie toegepast en met steeds groter succes. De kans op aanvalsvrijheid is nu ca. $70 \%$. De inclusiecriteria zijn verruimd en ook worden steeds gecompliceerdere operaties verricht in gespecialiseerde centra (Baud et al., 20I8). Tegenwoordig is het advies bij een focale epilepsie, zeker bij een structurele focale afwijking, om altijd de mogelijkheden van epilepsiechirurgie te evalueren, of te verwijzen naar een daarin gespecialiseerd (epilepsie)centrum en dit zo vroegtijdig mogelijk te doen (Braun et al., 2020).

Het is al langer bekend dat het langdurig bestaan van een actieve epilepsie bij kinderen invloed heeft op de cognitieve ontwikkeling (van Itterson et al., 20I4). Steeds meer onderzoeken tonen aan dat epilepsie, ontstaan op de vroege kinderleeftijd, een grote invloed heeft op de ontwikkeling, naast het gebruik van (de vaak combinaties) van anti-epileptica (Reilly et al, 20rga). Nederlands onderzoek laat zien dat bij succesvolle epilepsiechirurgie, na afbouwen en geheel staken van deze anti-epileptica, het postoperatieve IQ en de ontwikkeling verbetert. Dit effect is groter als er meerdere anti-epileptica werden gebruikt (Boshuisen et al., 20I5).

\section{Postoperatieve depressie en angst}

Psychiatrische co-morbiditeit in de voorgeschiedenis is bij volwassenen na epilepsiechirurgie de belangrijkste risicofactor voor het krijgen van postoperatieve depressie en angst (Fasano \& Kanner, 2019). Over kinderen is minder informatie bekend. De ontwikkeling van kinderen met epilepsie wordt ook beïnvloed door de vaak voorkomende co-morbiditeit, zoals autisme en ADHD (Lin et al., 2012). Autisme is bij ca. $30 \%$ van de kinderen met epilepsie aanwezig, met name als er ook cognitieve stoornissen zijn (Tuchman et al., 20I0). Dit is niet gekoppeld aan specifieke epilepsiesyndromen (Lin et al., 20I2). Bij kinderen met epilepsie komen ook ADHD-kenmerken in hoge mate voor, tot ca 70\% (Williams et al., 20I6), evenals depressie (8\%) en angststoornissen ( $17 \%$ ) (Russ et al., 20I2). Deze vormen van co-morbiditeit zijn niet altijd bekend bij het begin van de epilepsie, zeker niet als de epilepsie op heel jonge leeftijd ontstaat. Bij de prechirurgische screening in 
SEIN wordt behalve de algehele en cognitieve ontwikkeling, ook uitgebreid het psychologisch en psychiatrisch functioneren alsook de draagkracht van het steunsysteem geëvalueerd. Deze onderzoeken worden herhaald na de operatie. McLellan et al. (2005) toonden bij kinderen met een temporaalkwabepilepsie een hoge mate van co-morbiditeit aan, vaak ADHD en een autisme spectrum stoornis, die in gelijke mate aanwezig blijft na de operatie. Er zijn enige aanwijzingen dat het emotioneel functioneren en gedrag verbetert na epilepsiechirurgie, maar dit is met name gebaseerd op vragenlijsten ingevuld door de ouders en kon niet worden bevestigd in de studies die klinische diagnoses rapporteerden (Reilly et al., 20Igb).

De kwaliteit van leven verbetert na epilepsiechirurgie, met name bij aanvalsvrijheid, maar psychiatrische co-morbiditeit zoals depressie- en angstklachten blijven bestaan

(Tavares et al., 20I5). Het gebruik van anti-epileptica lijkt geen invloed te hebben op deze vormen van co-morbiditeit. In enkele gevallen ontstaat na de operatie psychiatrische co-morbiditeit. Het is mogelijk dat de epilepsie en de anti-epileptica, deze psychiatrische co-morbiditeit eerder maskeerde, of dat met het ouder worden de psychiatrische diagnose duidelijker wordt (Reilly et al., 2orgb). Duidelijke risicofactoren voor het ontwikkelen van psychiatrische co-morbiditeit zijn nu niet aan te wijzen. Goede studies die na epilepsiechirurgie de psychiatrische co-morbiditeit evalueren, samen met de verandering van de anti-epileptica (Reilly et al., 20Igb), ontbreken. Ook een genetische kwetsbaarheid voor deze psychiatrische co-morbiditeit moet in de beoordeling betrokken worden.

\section{Beschouwing}

Terug naar onze patiënten. In de algemene bevolking komen psychiatrische stoornissen op kinderleeftijd regelmatig voor, en deze nemen toe met de leeftijd. Een Engelse epidemiologische studie toonde aan dat $2 \%$ tot $4 \%$ van de vierjarigen een psychiatrische stoornis heeft, toenemend tot $16,9 \%$ van de zeventien tot negentienjarigen (Reilly et al., 20Igb). Deze prevalentie is zoals eerder genoemd, verhoogd bij kinderen met epilepsie. Bij onze eerste patiënte komen de psychiatrische problemen in de loop van het ouder worden steeds meer naar voren, terwijl haar sociaal-emotionele ontwikkeling duidelijk anders is dan die van haar tweelingzus. Anderzijds blijken een aantal gedragingen al langer te bestaan, maar werden deze eerder altijd aan de epilepsie geweten. De presentatie van haar aanvallen in de spreekkamer veranderde en de verdenking op PNEA wordt met hernieuwde langdurige videoEEG registratie bevestigd. De psychiatrische evaluatie naar een autisme spectrum stoornis is nog in volle gang. Op een jonge leeftijd is het moeilijk om deze diagnose te stellen en waarschijnlijk maskeerden de vele aanvallen, zie- kenhuisopnames en het gebruik van de anti-epileptica dit beeld.

Casus 2 illustreert dat ondanks de behaalde aanvalsvrijheid na epilepsiechirurgie en vergelijkbaar cognitieve scores preen postoperatief, het niet lukt een vervolgopleiding te doen en goed mee te komen in de maatschappij. Bij de pre- en postoperatieve neuropsychologische evaluatie worden behalve de cognitieve scores ook uitgebreid psychiatrische co-morbiditeit en algemeen welbevinden geëvalueerd. Haar pre-existente psychiatrische co-morbiditeit is onveranderd aanwezig. Haar angsten nemen zelfs toe. De multidisciplinaire begeleiding door een psycholoog en medisch maatschappelijk werk bij SEIN moeten worden geïntensiveerd. Ondanks dat het in de loop van de tijd beter gaat is behandeling nog steeds geïndiceerd.

\section{Conclusie}

Allereerst is het zeer van belang om bij een kind met een focale therapieresistente epilepsie, zeker met een onderliggende structurele laesie, op zo jong mogelijke leeftijd aan de mogelijkheden van epilepsiechirurgie te denken en te verwijzen naar een daarin gespecialiseerd (epilepsie) centrum.

Bij kinderen met epilepsie (met en zonder epilepsiechirurgie) komt psychiatrische co-morbiditeit veelvuldig voor, die soms pas op oudere leeftijd duidelijker aanwezig is. Pre- en postoperatieve neuropsychologische evaluatie is daarmee geïndiceerd, niet alleen om de algehele ontwikkeling in kaart te brengen, maar ook om (psychiatrische) risicofactoren te beschrijven voor een operatie en de juiste begeleiding te bieden voor ouders en kind rondom het epilepsiechirurgietraject. Verder is bij terugkeer van klachten na succesvolle epilepsiechirurgie hernieuwde diagnostiek noodzakelijk, zeker als de presentatie anders is dan voorheen.

\section{Referenties}

Baud MO, Perneger T, Rácz A et al. (2018). European trends in epilepsy surgery. Neurology, 9I(2):96-Io6. Boshuisen K, van Schooneveld MM, Uiterwaal CS, JH et. al. (2015); Time'ToStop cognitive outcome study group. Intelligence quotient improves after antiepileptic drug withdrawal following pediatric epilepsy surgery. Ann Neurol.75:I04-I4.

Braun KPJ. (2020) Influence of epilepsy surgery on developmental outcomes in children. Eur J Paediatr Neurol. 24:40-42.

Fasano RE, Kanner AM (20I9). Psychiatric complications after epilepsy surgery...but where are the psychiatrist. Epilepsy Behav.98 (pt B) :318-32I. 
Lin JJ, Mula M, Hermann BP (2012). Uncovering the neurobehavioural comorbidities of epilepsy over lifespan. Lancet 380 (9848): II 80-92.

McLellan A, Davies S, Heyman I, et al. (2005). Psychopathology in children with epilepsy before and after temporal lobe resection. Dev Med Child Neurol. 47(Io):666-72.

Reilly C.Atkinson P, Memon A, et al (2019a). Global development and adaptive behaviour in children with earlyonset epilepsy: a population-based case-control study. Dev Med Child Neurol. 6I(2):I45-I5I.

Reilly C, Baldeweg T, Stewart N et al. (20Igb). Do behavior and emotions improve after pediatric epilepsy surgery? A systematic review. Epilepsia. 6o(5):885-897.

Russ SA., Larson K, Halfon N (2012). A national profile of childhood epilepsy and seizure disorder. Pediatrics. I29(2):256-64.
Tavares TP, Puka K, Smith ML, (20I5). Emotional functioning: Long-term outcomes after pediatric epilepsy surgery. Epilepsia. 56(5):745-53.

Tuchman R., Alessandri M, Cuccaro M (20I0). Autism spectrum disorders and epilepsy: moving towards a comprehensive approach to treatment. Brain Dev. 32(9):719-30.

Van Itterson L, Zijlstra B.J, Augustijn PB et al (20I4). Duration of epilepsy and cognitive development in children: a longitudinal study Neuropsychology; 28(2):2I2-22I.

Williams AE, Giust JM, Kronenberger WG, et al. 2016 Epilepsy and attention-deficit hyperactivity disorder: links, risks, and challenges. Neuropsychiatr Dis Treat;(I2):287-96.

\section{Epilepsi $\Longrightarrow N L$}

\section{Subsidies voor epilepsieonderzoek startend in 2023}

EpilepsieNL wil wetenschappelijk onderzoek stimuleren en stelt daarom subsidies beschikbaar voor onderzoeksprojecten over epilepsie en de behandeling/bestrijding daarvan.

Uitgangspunt is dat de instelling waarbij de onderzoeker werkt een belangrijke inbreng heeft in het te subsidiëren onderzoek. De subsidie heeft in principe een aanvullend karakter. Belangrijke beoordelingscriteria zijn kwaliteit van het onderzoek en klinische en maatschappelijk relevantie. Projecten mogen in principe de duur van vier jaar niet overschrijden. Bij een combinatie van een specialistenopleiding en wetenschappelijk onderzoek behoort een langere duur van het project, binnen eenzelfde budget, tot de mogelijkheden.

Subsidieaanvragen voor onderzoeken die in 2023 beginnen kunnen bij EpilepsieNL worden ingediend tot en met 15 januari 2022. In het voorjaar 2022 wordt uit de ontvangen subsidieaanvragen de eerste selectie gemaakt door de Wetenschappelijke Adviesraad van EpilepsieNL. In juni 2022 wordt een besloten hoorzitting gehouden. Subsidieaanvragers die door de eerste selectieronde heen zijn, kunnen voor deze hoorzitting worden uitgenodigd om hun onderzoeksvoorstel nader toe te lichten aan de Wetenschappelijke Adviesraad.

\section{Een aanvraag indienen?}

Subsidieaanvraagformulieren kunt u in najaar 2021 vinden op www.epilepsie.nl onder het kopje 'Onderzoek' en vervolgens 'Voor onderzoekers'. Daar kunt u ook alle informatie over het aanvragen van subsidie vinden.

\section{EpilepsieNL}

Secretariaat Wetenschappelijke Adviesraad

Postbus 270

3990 GB HOUTEN

Telefoon: 0306344063

E-mail: patricia@epilepsie.nl 